Rapid Reviews COVID-19

\title{
Reviews of "Estimated transmissibility and severity of novel SARS- CoV-2 Variant of Concern 202012/01 in England"
}

Tomasz Lipniacki ${ }^{1}$, Frederic Grabowski, Marek Kochańczyk, Seyed Hasnain ${ }^{2}$

${ }^{1}$ Institute of Fundamental Technological Research, Biosystems and Soft Matter, Poland,

${ }^{2}$ Honorary Professor, Jamia Hamdard, DBEB, India

Published on: Feb 10, 2021

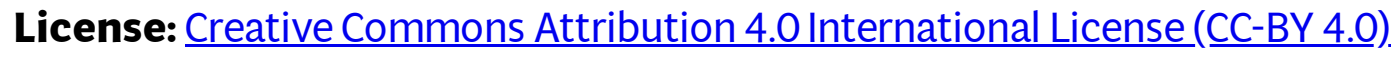


To read the original manuscript, click the link above.

Summary of Reviews: This potentially informative study models the spread of 501Y.V1 in England, and suggests more stringent control measures and increased vaccinations are necessary to prevent spread of these variants.

Reviewer 1 (Tomasz Lipniacki, Frederic Grabowski, Marek Kochańczyk) |

Reviewer 2 (Seyed Hasnain) | $\square \square \square \square \square$

RR:C19 Strength of Evidence Scale Key.

$\square \square \square \square \square=$ Misleading

$\square \square \square \square$ = Not Informative

$\square \square \square \square=$ Potentially Informative

पढ口 $\square=$ Reliable

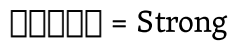

To read the reviews, click the links below. 